Solomon Poll, The Hasidic Community of Williamsburg. A Study in the Sociology of Religion

Introd. de William B. Helmreich. New Brunswick, London, Transaction Publishers, 2006, $\mathrm{xv}+308 \mathrm{p}$.

Jacques Gutwirth

\title{
CpenEdition
}

Journals

Édition électronique

URL : http://journals.openedition.org/assr/6942

DOI : 10.4000/assr.6942

ISSN : $1777-5825$

Éditeur

Éditions de l'EHESS

Édition imprimée

Date de publication : 1 juin 2007

Pagination : $97-251$

ISBN : 978-2-7132-2143-9

ISSN : 0335-5985

Référence électronique

Jacques Gutwirth, « Solomon Poll, The Hasidic Community of Williamsburg. A Study in the Sociology of Religion ", Archives de sciences sociales des religions [En ligne], 138 | avril - juin 2007, document 138-72, mis en ligne le 17 septembre 2007, consulté le 21 septembre 2020. URL : http:// journals.openedition.org/assr/6942; DOI : https://doi.org/10.4000/assr.6942

Ce document a été généré automatiquement le 21 septembre 2020.

(c) Archives de sciences sociales des religions 


\section{Solomon Poll, The Hasidic Community of Williamsburg. A Study in the Sociology of Religion}

Introd. de William B. Helmreich. New Brunswick, London, Transaction

Publishers, 2006, $\mathrm{xV}+308 \mathrm{p}$.

Jacques Gutwirth

1 Il s'agit de la réédition d'un livre pionnier sur les hassidim des États-Unis, publié en 1962 par Free Press à New York. S. Poll avait notamment montré avec nombre de détails ethnographiques, l'importance des activités économiques des hassidim, en bonne partie associées aux normes judaïques en matière de cashrout, de vêtements ne mélangeant pas le lin et la laine (loi du shatnes), d'articles religieux, etc. Par leur intransigeance en la matière, les hassidim avaient mis en vigueur des exigences que d'autres commerces moins rigoureux ne satisfaisaient pas ; c'était là un atout pour la réussite de leur implantation à Brooklyn, après la Seconde Guerre mondiale. Le préfacier note que, près de cinquante ans plus tard, Williamsburg n'a pas beaucoup changé. De nouveaux quartiers hassidiques se sont développés à Brooklyn, notamment à Boro Park, et, d'autre part, la principale communauté hassidique de Williamsburg, les Satmarer, a fondé une "filiale », le village de Kiryas Joel, en zone rurale, à quatrevingts kilomètres de New York. Il est vrai, note-t-il, qu'aujourd'hui le torchon brûle entre ces deux pôles Satmar.

2 Poll avait montré les méthodes du contrôle social à Williamsburg. Les déviants étaient sanctionnés économiquement: leurs commerces n'étaient plus patronnés par les communautés hassidiques et leurs fidèles. De plus, ils ne recevaient plus le soutien d'un ensemble d'organisations caritatives, enfin les non-conformistes faisaient l'objet de ragots et de sarcasmes. Ces méthodes restent quelque peu efficaces, mais aujourd'hui des crises se profilent. La drogue et l'alcool, la promiscuité sexuelle et le rejet de l'observance religieuse touchent de nombreuses familles. Une des menaces essentielles, que les hassidim ont du mal à esquiver, est l'usage d'internet, précieux pour d'innombrables occupations, mais qui apporte une ouverture majeure sur le monde: 
internet expose désormais les hassidim, surtout les jeunes, à la musique et à la culture non religieuse, et en particulier à la pornographie. D'ailleurs, aujourd'hui les déviants ne sont plus isolés car il existe des sites web et des organisations pour les aider à rechercher un travail ou à accéder à des études profanes. (Voir mon compte rendu du livre de Hella Winston in ASSR 138-99).

3 L'ouvrage de Poll, décédé en 2004, méritait bien cette réédition. 